\title{
UJI FITOKIMIA DAN UJI ANTIBAKTERI DARI AKAR MANGROVE Rhizopora apiculata TERHADAP BAKTERI Escherichia coli DAN Staphylococcus aureus
}

\author{
Phytochemical Test and Antibacterial Test of Rhizopora apiculata Mangrove- \\ Root against Escherichia coli and Staphylococcus aureus Bacteria
}

\begin{abstract}
Usman *
Program Studi Magister Pendidikan Kimia, FKIP, Universitas Mulawarman Jl. Muara Pahu Kampus Gn. Kelua, Samarinda, Kalimantan Timur, Indonesia

*Untuk korespondensi: e-mail: sainusman@ymail.com

ABSTRAK

Indonesia memiliki berbagai jenis mangrove namun pemanfaatan mangrove sebagai produk obat dan makanan kesehatan belum banyak dimanfaatkan karena masih terbatasnya informasi dan penelitian mengenai kandungan senyawa bioaktif pada tumbuhan mangrove. Salah satu spesies mangrove yang banyak ditemukan di kawasan hutan mangrove Bontang Kalimantan Timur adalah $R$. apiculata. Tumbuhan ini dimanfaatkan oleh masyarakat pesisir sebagai bahan bakar, bahan bangunan, bahan pembuatan kapal, dan sebagai bahan obat tradisional. Penelitian ini bertujuan untuk mengetahui golongan senyawa metabolit sekunder dan aktivitas antibakteri ekstrak metanol akar mangrove $R$. apiculata. Ekstraksi dilakukan dengan metode maserasi dengan menggunakan pelarut metanol. Golongan senyawa metabolit sekunder yang terkandung pada sampel mangrove tersebut ditentukan secara kualitatif dengan menggunakan beberapa pereaksi uji fitokimia. Metode yang digunakan untuk uji antibakteri terhadap E. coli dan S. aureus adalah metode difusi dengan variasi konsentrasi ekstrak metanol akar mangrove $R$. apiculata 500 $\mu \mathrm{g} / \mathrm{well}, 250 \mu \mathrm{g} / \mathrm{well}$, dan $125 \mu \mathrm{g} / \mathrm{well}$ serta variasi waktu inkubasi $12 \mathrm{jam}, 24 \mathrm{jam}, 48 \mathrm{jam}$, dan 72 jam. Berdasarkan hasil uji Fitokimia dapat disimpulkan bahwa ekstrak metanol akar mangrove $R$. apiculata mengandung golongan senyawa metabolit sekunder: alkaloid, flavonoid, dan triterpenoid. Hasil uji antibakteri ekstrak metanol akar mangrove $R$. apiculata mampu menghambat pertumbuhan bakteri $S$. aureus pada konsentrasi $500 \mu \mathrm{g} /$ well dengan waktu inkubasi 12 jam, 24 jam, 48 jam, dan 72 jam dengan zona hambat masing-masing 7.95 mm, 8.3 mm, 8.0 mm, dan $7.0 \mathrm{~mm}$. Pada konsentrasi $250 \mu \mathrm{g} /$ well dengan waktu inkubasi 48 jam memiliki zona hambat $7.5 \mathrm{~mm}$. Namun ekstrak metanol akar mangrove $R$. apiculata tidak menghambat pertumbuhan bakteri Escherichia coli. Berdasarkan data zona hambatan pada uji antibakteri terhadap S. aureus dapat disimpulkan bahwa aktivitas antibakteri ekstrak metanol akar mangrove $R$. apiculata terhadap S. aureus tergolong kategori lemah.
\end{abstract}

Kata kunci: Rhizophora apiculata, senyawa metabolit sekunder, antibakteri

\section{ABSTRACT}

Indonesia has many kinds of mangrove but they have not been widely utilized as health food and medicinal products because of the limited information and research on the content of bioactive compounds in the mangroves. One of the mangrove species that are found in the 
Bontang mangrove forest, East Kalimantan is R. apiculata. It is used as fuel, building materials, shipbuilding, and as traditional medicine. This study aims to determine the class of secondary metabolites compounds and the antibacterial activity of methanol extract of $R$. apiculata mangrove roots. The extraction was performed by maceration method using methanol solvent. Secondary metabolites compounds class in the mangrove sample was determined qualitatively by using several phytochemical reagents. Antibacterial test against E. coli and $S$. aureus were performed using diffusion method with various concentration of the roots-mangrove methanol extract of 500, 250, and $125 \mathrm{ug} /$ well. Incubation was performed in various time of 12, 24, 48 and 72 hours. Phytochemical test results showed that the roots-mangrove methanol extract of $R$. apiculata contained secondary metabolites classes of alkaloids, flavonoids and triterpenoids. The extract does not inhibit the growth of E. coli, but it could inhibit the growth of S. aureus at $500 \mathrm{ug}$ / well with incubation time of 12, 24, 48 and 72 hours and have inhibition zones of $7.95 \mathrm{~mm}, 8.3$ $\mathrm{mm}, 8.0 \mathrm{~mm}$, and $7.0 \mathrm{~mm}$, respectively. At a concentration of $250 \mathrm{ug} /$ well with an incubation time of 48 hours has a $7.5 \mathrm{~mm}$ of inhibition zone. Those inhibitions are relatively weak category.

Keywords: Rhizophora apiculata, secondary metabolites compounds, antibacterial

\section{PENDAHULUAN}

Pemanfaatan tumbuhan untuk pengobatan secara tradisional telah diwariskan secara turun temurun untuk mengobati berbagai penyakit. Salah satu jenis tumbuhan yang berpotensi sebagai sumber bahan obat tradisional adalah tumbuhan mangrove karena tumbuhan ini mengandung senyawa bioaktif, diantaranya senyawa golongan; alkaloid, steroid, terpenoid, saponin, dan tanin serta senyawa golongan flavonoid dan quinon dengan berbagai bioaktivitas seperti antimikroba, antifungi, antivirus, antitumor, antileukemia, dan insektisida $[1,2]$.

Ekstrak dari beberapa jenis tumbuhan mangrove seperti Rhizophora stylosa, Soneratia griffithi, Aegiceras floridum dan Excoecaria agallocha memiliki daya hambat terhadap pertumbuhan $S$. aureus. Ekstrak kloroform kulit batang mangrove bersifat toksik terhadap ulat grayak dan berpotensi sebagai bioinsektisida alami [3]. Hasil uji daya toksissitas larva serangga nyamuk Culex quinquefasciatus dengan menggunakan ekstrak beberapa jenis mangrove dari genus Rhizophoraceae diantaranya adalah $R$. apiculata, R. lamarckii, dan $R$. mucronata. Hasil uji tersebut menunjukkan ekstrak petroleum eter $R$. apiculata yang paling toksik terhadap larva nyamuk Culex quinquefasciatus dengan nilai $\mathrm{LC}_{50}$ sebesar 25,7 mg/L [3].

Beberapa senyawa metabolit sekunder telah diisolasi dari tumbuhan mangrove diantaranya senyawa golongan steroid yaitu kampesterol (ergost-5-en-3-ol), stigmasterol (stigmas-5,22-dien-3-ol), dan $\beta$-Sitosterol (stigmast-5-em-3-ol) dari ekstrak diklorometana kulit batang $R$. stylosa [2]. Senyawa golongan flavonoid yaitu 3,7-O-diasetil (--)-epikatecin, 3-Oasetil (--)-epikatecin, 3,3'4',5,7-O-pentaasetil (--)epikatecin, (+)-afzelecin, kinkonain Ib, dan proantosianidin B2 dari ekstrak metanol batang dan ranting $R$. stylosa [4]. Kemudian dua senyawa golongan steroid yang diisolasi dari ekstrak kloroform kulit batang $R$. mucronata yaitu 4-metil-kolest-24-en-3-ol dan 4-metilstigmast-22-en-3-ol. Serta senyawa $\beta$-Sitosterol yang diisolasi dari ekstrak metanol kulit batang $R$. mucronata yang memiliki aktivitas antiinflamasi dan antidiare [5].

Salah satu spesies tumbuhan mangrove yang banyak ditemukan di di kawasan hutan 
mangrove Bontang Kalimantan Timur adalah $R$ apiculata. Tumbuhan ini digunakan oleh masyarakat pesisir sebagai bahan bakar, bahan bangunan, dan bahan pembuatan kapal, serta sebagai obat tradisional untuk mengobati penyakit disentri, dan melangsingkan badan.

Penggunaan tanaman mangrove yang berasal dari kawasan hutan mangrove Bontang Kaltim sebagai antijamur belum pernah dipublikasikan secara ilmiah. Sehingga perlu dilakukan penelitian terhadap tumbuhan mangrove terutama spesies $R$ apiculata yang berasal dari kawasan hutan mangrove Bontang Kaltim mengenai bioaktivitasnya dan senyawa metabolit sekunder yang terkandung pada tanaman mangrove tersebut yang dapat dijadikan sebagai sumber bahan obat antibakteri baru.

\section{METODE PENELITIAN}

Bahan yang digunakan dalam penelitian adalah sampel akar mangrove $R$. apiculata, metanol, aquades, kloroform, larutan $\mathrm{H}_{2} \mathrm{SO}_{4}$ pekat, larutan $\mathrm{HCl} 2 \mathrm{~N}$, larutan Dragendorff, larutan $\mathrm{NaOH}$ 1\%, kertas label, kertas saring, aluminium foil, tisu, vaselin, kapas steril, etanol $70 \%$ dan $40 \%$, agar, glukosa, nutrient broth (NB), kloramfenikol, bakteri $E$. coli, bakteri $S$. aureus.

\section{Prosedur Kerja}

\section{a. Pengolahan Sampel.}

Sampel yang digunakan dalam penelitian ini adalah akar mangrove $R$ apiculata yang diambil dari Kawasan Mangrove Bontang, Kalimantan Timur. Sampel akar mangrove yang telah dikumpulkan dibersihkan lalu dikeringkan di udara terbuka. Selanjutnya sampel tersebut dipotong-potong kecil lalu digiling sehingga diperoleh sampel berbentuk serbuk halus sebanyak 500 gram dengan ukuran 90 mesh.

\section{b. Ekstraksi dengan cara maserasi}

Sebanyak 500 gram serbuk halus akar mangrove $R$. apiculata diekstraksi dengan cara maserasi dengan menggunakan pelarut metanol selama 1 x 24 jam (sebanyak 3 kali). Maserat yang diperoleh disaring dan ditampung dalam Erlenmeyer serta senyawa yang terkandung pada ekstrak metanol dimonitoring dengan KLT. Ketiga maserat tersebut digabung kemudian dipekatkan pelarutnya dengan menggunakan rotary evaporator hingga diperoleh ekstrak metanol pekat yang berwarna cokelat kehitaman dan ditentukan rendamennya.

\section{c. Uji Fitokimia}

Ekstrak metanol yang diperoleh, dilanjutkan dengan uji fitokimia Uji fitokimia yang dilakukan adalah; uji alkaloid dengan pereaksi Meyer, Wagner dan Dragendorf; uji flavonoid dengan pereaksi (serbuk Mg dalam $0,2 \mathrm{ml} \mathrm{HCl}$ pekat), uji fenolik dengan pereaksi $\mathrm{FeCl}_{3}$, uji triterpenoid dan steroid dengan pereaksi LB dan Salkowski serta Uji saponin dengan pereaksi busa.

\section{d. Uji Antibakteri.}

Bakteri uji yang digunakan dalam penelitian ini adalah $S$. aureus (bakteri gram positif) dan E. coli (bakteri gram negatif). Pengujian daya hambat ekstrak metanol akar mangrove $R$ apiculata terhadap bakteri uji dilakukan dengan metode difusi agar. Konsentrasi ekstrak metanol akar mangrove $R$. apiculata 
berbeda-beda yaitu; $500 \mu \mathrm{g} / \mathrm{well}, 250 \mu \mathrm{g} /$ well, $125 \mu \mathrm{g} /$ well. Kontrol positf yang digunakan adalah kloramfenikol $0,5 \mathrm{mg} / \mathrm{mL}$, sedangkan kontrol negatif yang digunakan adalah etanol $40 \%$. Skema penelitian dapat dilihat pada Gambar 1.

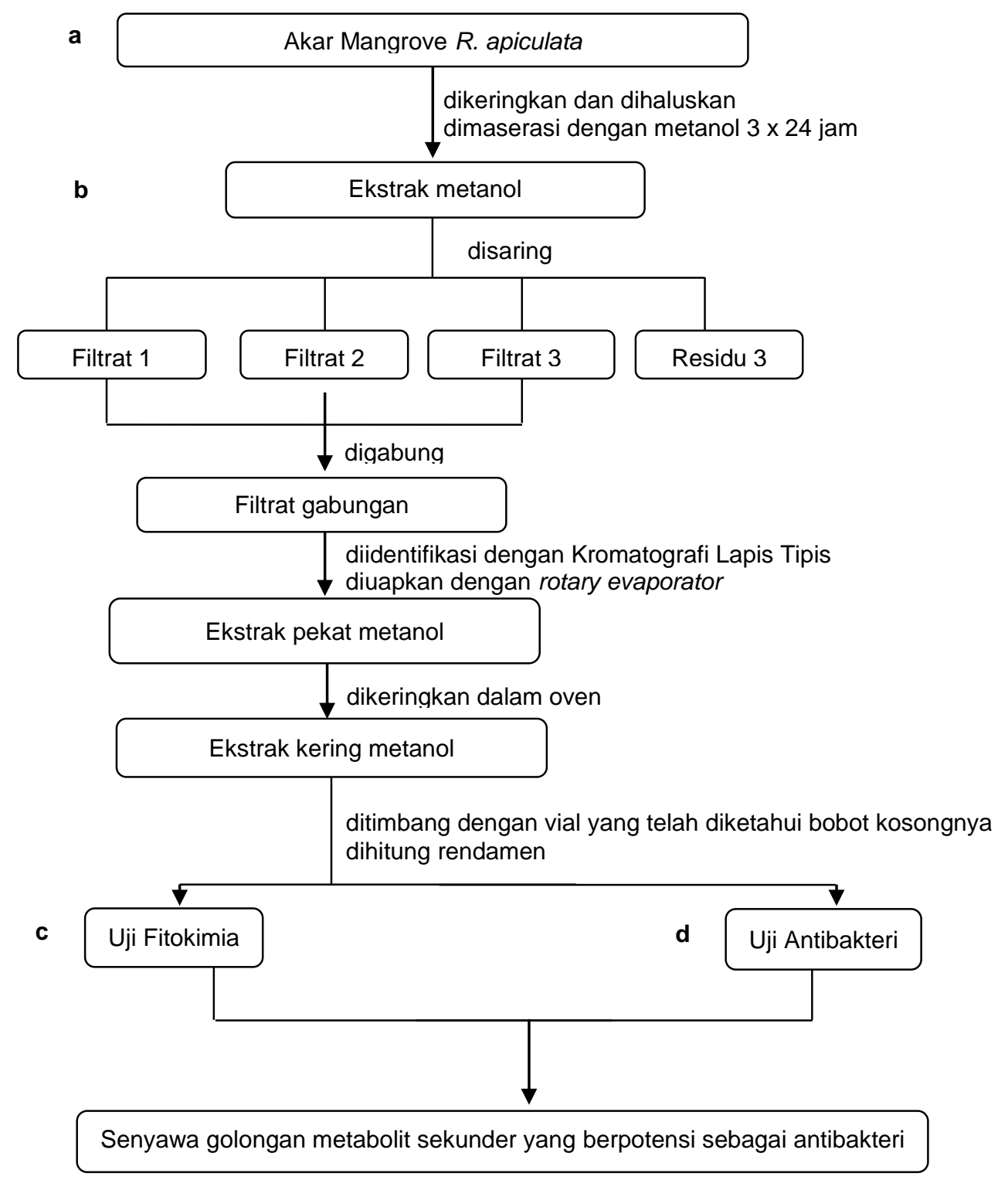

Gambar 1. Skema Penelitian, a. Pengolahan Sampel, b. Ekstraksi dengan Cara Maserasi, c. Uji Fitokimia, dan d. Uji Antibakteri

\section{HASIL DAN PEMBAHASAN}

Ekstrak metanol yang diperoleh dari hasil maserasi yang diuapkan dengan menggunakan alat rotary vacuum evaporator dan dihasilkan ekstrak pekat metanol yang berwarna coklat kehitaman sebanyak 36,46 gram.

Uji Fitokimia merupakan metode pendekatan yang digunakan dalam menentukan keberadaan senyawa metabolit sekunder pada tanaman. Golongan senyawa 
metabolit sekunder ditentukan secara kualitatif dengan menggunakan beberapa pereaksi uji fitokimia. Golongan Senyawa metabolit sekunder yang terkandung dalam ekstrak diketahui dengan adanya perubahan warna, pengendapan atau pembentukan busa sesuai dengan pereaksi yang digunakan. Hasil uji fitokimia ekstrak metanol akar mangrove $R$. apiculata dapat dilihat pada Tabel 1.

Tabel 1. Hasil uji fitokimia ekstrak metanol akar mangrove $R$. apiculata

\begin{tabular}{ccccc}
\hline No & $\begin{array}{c}\text { Golongan } \\
\text { Senyawa }\end{array}$ & Pereaksi & Perubahan & Hasil \\
\hline & & Dragendorf & Merah-kekuningan & + \\
1 & Alkaloid & Meyer & Endapan putih & + \\
& & Wagner & Tidak ada perubahan & - \\
2 & Flavonoid & Mg $+\mathrm{HCl} \mathrm{2 \%}$ & Merah/Jingga & + \\
3 & Steroid & Lieberman-Burchard & Tidak ada perubahan & - \\
4 & Triterpenoid & Lieberman-Burchard & Merah & + \\
5 & Saponin & Air panas $+\mathrm{HCl}$ & Tidak terbentuk busa stabil & - \\
\hline
\end{tabular}

Berdasarkan hasil uji Fitokimia golongan senyawa metabolit sekunder yang terkandung pada ekstrak metanol akar mangrove $R$. apiculata yaitu senyawa alkaloid, flavonoid, dan triterpenoid sedangkan senyawa steroid dan sponin tidak ditemukan dalam ekstrak metanol akar mangrove $R$. apiculata.

Hasil uji fitokimia pada spesies mangrove $R$. mucronata menunjukkan bahwa hampir seluruh bagian tanaman tersebut mengandung golongan senyawa alkaloid, saponin, tanin dan flavonoid [6]. Hail penelitian lain terhadap beberapa jenis mangrove melaporkan bahwa kandungan senyawa metabolit sekunder pada tanaman tersebut adalah golongan senyawa alkaloid, fenolik, steroid, dan terpenoid dimana kandungan senyawa aktif tersebut bersifat toksik dan farmakologik [7]. Kandungan senyawa metaboli sekunder yang terdapat dalam daun mangrove adalah golongan senyawa; fenolik, alkaloid, dan saponin [8]. Hasil penelitian menunjukkan bahwa perbedaan jenis pelarut yang digunakan untuk mengekstrak berpengaruh terhadap komponen kimia yang diekstrak pada pada tanaman. Pelarut metanol mampu mengekstrak senyawa alkaloid, fenolik, karotenoid dan tanin, pelarut heksan dapat mengekstrak triterpenoid/ steroid, sedangkan komponen kimia yang mampu larut dalam pelarut etil asetat yaitu senyawa fenolik, flavonoid dan terpenoid yang merupakan senyawa metabolit sekunder yang dapat diperoleh pada bagian jaringan daun, akar, kayu batang, kulit batang, bunga, dan biji [5,9].

Hasil uji aktivitas antibakteri ekstrak metanol akar mangrove dengan konsentrasi $500 \mu \mathrm{g} / \mathrm{well}, 250 \mu \mathrm{g} / \mathrm{well}$, dan $125 \mu \mathrm{g} / \mathrm{well}$ terhadap bakteri $S$. aureus dan bakteri E. coli dengan waktu inkubasi 12 jam, 24 jam, 36 jam, 48 jam, dan 72 jam dapat dilihat pada Tabel 2 dan 3. 
Tabel 2. Hasil uji aktivitas antibakteri ekstrak metanol akar mangrove $R$. apiculata terhadap bakteri $S$. aureus

\begin{tabular}{|c|c|c|c|c|c|c|}
\hline \multirow{3}{*}{ Waktu } & \multirow{3}{*}{ Replikasi } & \multicolumn{5}{|c|}{$\begin{array}{c}\text { Diameter zona hambat (mm) } \\
\text { Bakteri S. aureus }\end{array}$} \\
\hline & & \multirow[b]{2}{*}{ Kontrol negatif } & \multirow[b]{2}{*}{ Kontrol positif } & \multicolumn{3}{|c|}{ Ekstrak akar R. apiculata } \\
\hline & & & & $\begin{array}{c}500 \\
\mu g / \text { well }\end{array}$ & $\begin{array}{c}250 \\
\mu g / w e l l\end{array}$ & $\begin{array}{c}125 \\
\mu g / \text { well }\end{array}$ \\
\hline \multirow{3}{*}{12 jam } & 1 & 7.0 & 24 & 7.6 & 7.0 & 7.0 \\
\hline & 2 & 7.0 & 26 & 8.3 & 7.0 & 7.0 \\
\hline & Rata-rata & 7.0 & 25 & 7.95 & 7.0 & 7.0 \\
\hline \multirow{3}{*}{24 jam } & 1 & 7.0 & 25 & 8.6 & 7.0 & 7.0 \\
\hline & 2 & 7.0 & 23 & 8.0 & 7.0 & 7.0 \\
\hline & Rata-rata & 7.0 & 24 & 8.3 & 7.0 & 7.0 \\
\hline \multirow{3}{*}{48 jam } & 1 & 7.0 & 22 & 8.0 & 8.0 & 7.0 \\
\hline & 2 & 7.0 & 23 & 8.0 & 7.0 & 7.0 \\
\hline & Rata-rata & 7.0 & 22.5 & 8.0 & 7.5 & 7.0 \\
\hline \multirow{3}{*}{72 jam } & 1 & 7.0 & 27 & 7.0 & 7.0 & 7.0 \\
\hline & 2 & 7.0 & 25 & 7.0 & 7.0 & 7.0 \\
\hline & Rata-rata & 7.0 & 26 & 7.0 & 7.0 & 7.0 \\
\hline
\end{tabular}

Tabel 3. Hasil uji aktivitas antibakteri ekstrak metanol akar mangrove $R$. apiculata terhadap bakteri E. coli

\begin{tabular}{|c|c|c|c|c|c|c|}
\hline \multirow{3}{*}{ Waktu } & \multirow{3}{*}{ Replikasi } & \multicolumn{5}{|c|}{$\begin{array}{c}\text { Diameter zona hambat }(\mathrm{mm}) \\
\text { Bakteri } E \text {. coli }\end{array}$} \\
\hline & & \multirow[b]{2}{*}{ Kontrol negatif } & \multirow[b]{2}{*}{ Kontrol positif } & \multicolumn{3}{|c|}{ Ekstrak akar $R$. apiculata } \\
\hline & & & & $\begin{array}{c}500 \\
\mu g / \text { well }\end{array}$ & $\begin{array}{c}250 \\
\mu \mathrm{g} / \text { well }\end{array}$ & $\begin{array}{c}125 \\
\mu \mathrm{g} / \text { well }\end{array}$ \\
\hline \multirow{3}{*}{12 jam } & 1 & 7.0 & 27.0 & 7.0 & 7.0 & 7.0 \\
\hline & 2 & 7.0 & 29.0 & 7.0 & 7.0 & 7.0 \\
\hline & Rata-rata & 7.0 & 28.0 & 7.0 & 7.0 & 7.0 \\
\hline \multirow{3}{*}{24 jam } & 1 & 7.0 & 25.0 & 7.0 & 7.0 & 7.0 \\
\hline & 2 & 7.0 & 23.0 & 7.0 & 7.0 & 7.0 \\
\hline & Rata-rata & 7.0 & 24.0 & 7.0 & 7.0 & 7.0 \\
\hline \multirow{3}{*}{48 jam } & 1 & 7.0 & 26.0 & 7.0 & 7.0 & 7.0 \\
\hline & 2 & 7.0 & 26.0 & 7.0 & 7.0 & 7.0 \\
\hline & Rata-rata & 7.0 & 26.0 & 7.0 & 7.0 & 7.0 \\
\hline \multirow{3}{*}{72 jam } & 1 & 7.0 & 23.0 & 7.0 & 7.0 & 7.0 \\
\hline & 2 & 7.0 & 21.0 & 7.0 & 7.0 & 7.0 \\
\hline & Rata-rata & 7.0 & 22.0 & 7.0 & 7.0 & 7.0 \\
\hline
\end{tabular}

Keterangan:

Kontrol negatif $=$ etanol $40 \%$

Kontrol positif $=$ kloramfenikol $0,5 \mathrm{mg} / \mathrm{mL}$ 


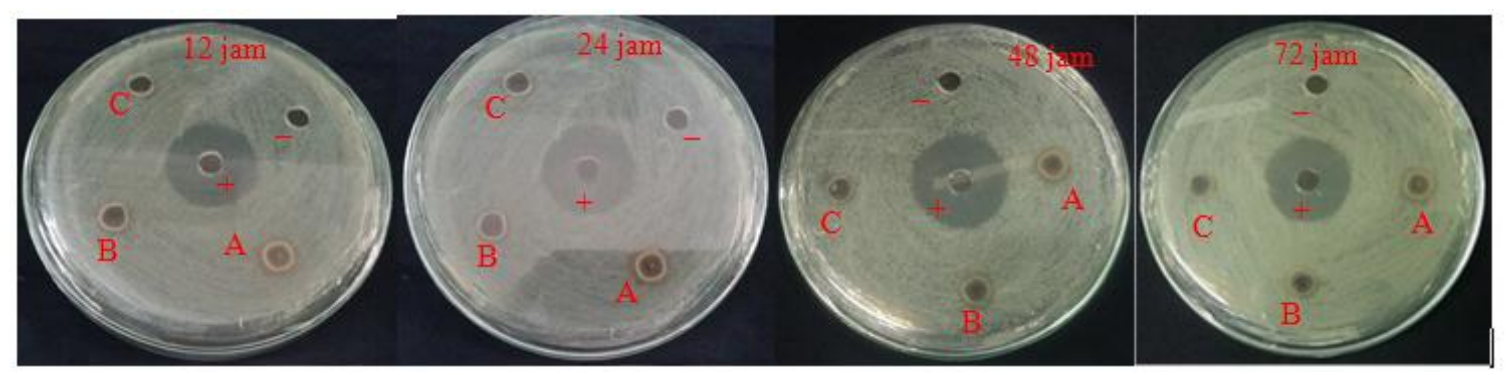

Gambar 2. Hasil zona hambat uji aktivitas antibakteri ekstrak metanol akar $R$. apiculata, kontrol positif, dan kontrol negatif terhadap bakteri $S$. aureus.

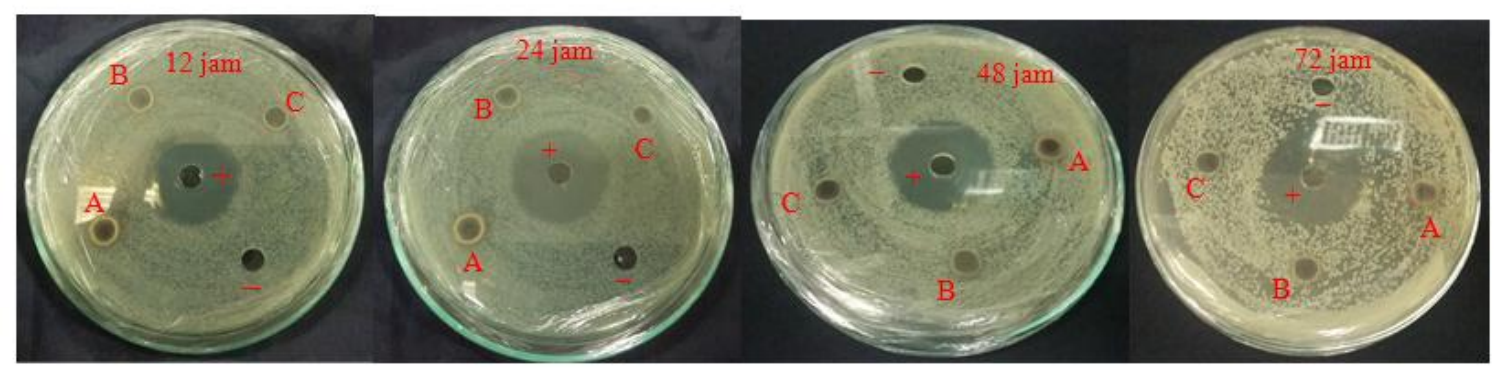

Gambar 3. Hasil zona hambat uji aktivitas antibakteri ekstrak metanol akar $R$. apiculata, kontrol positif, dan kontrol negatif terhadap bakteri E. coli.

\section{Keterangan:}

$(+),=$ kontrol positif (kloramfenikol $0,5 \mathrm{mg} / \mathrm{mL})$

$(-),=$ kontrol negatif (etanol $40 \%$ )

$[\mathrm{A}],=$ konsentrasi ekstrak $500 \mu \mathrm{g} / \mathrm{wel}$

[B]. = konsentrasi ekstrak $250 \mu \mathrm{g} /$ well

[C]. = konsentrasi ekstrak $125 \mu \mathrm{g} /$ well

Hasil pengujian aktivitas antibakteri ekstrak metanol akar $R$. apiculata dengan variasi konsentrasi $500 \mu \mathrm{L} /$ well, $250 \mu \mathrm{L} /$ well, dan $125 \mu \mathrm{L} /$ well terhadap pertumbuhan bakteri $S$. aureus dan $E$. coli denga waktu inkubasi; 12 jam, 24 jam, 48 jam dan 72 jam dapat dilihat pada gambar 2 dan 3

Berdasarkan hasil uji aktivitas antibakteri sebagaimana yang disajikan pada Tabel 2, menunjukkan bahwa ekstrak metanol dari akar mangrove $R$. apiculata pada konsentrasi $500 \mu \mathrm{L} /$ well dengan variasi waktu inkubasi yaitu 12 jam, 24 jam, 48 jam dan 72 jam memiliki daya hambat terhadap pertumbuhan bakteri $S$. aureus dengan zona hambat antara 7,0 - 8,3 mm. Pada konsentrasi $250 \mu \mathrm{L} /$ well dengan waktu inkubasi 48 jam hanya memperlihatkan daya hambat terhadap bakteri $S$. aureus dengan zona hambat $7.5 \mathrm{~mm}$. Sedangkan pada konsentrasi $125 \mu \mathrm{g} /$ well tidak menunjukkan daya hambat terhadap pertumbuhan bakteri uji. Daya hambat ekstrak metanol akar mangrove $R$. apiculata terhadap bakteri $S$. aureus tergolong kategori lemah. Sedangkan ekstrak metanol akar mangrove $R$. apiculata tidak menunjukkan daya hambat terhadap bakteri E. coli.

Ekstrak metanol akar mangrove $R$. apiculata memiliki aktivitas antibakteri 
terhadap bakteri $S$. aureus. Hal ini disebabkan oleh adanya golongan senyawa alkaloid yang terkandung pada ekstrak metanol tersebut dimana senyawa alkaloid dapat menggangu komponen penyusunanan peptidoglikan pada sel bakteri yang mengakibatkan dinding sel tidak tebentuk secara sempurna[10]. Daya hambat ekstrak metanol akar mangrove $R$. Apiculata terhadapa bakteri uji $S$. aureus termasuk kategori lemah, hal ini diakibatkan oleh dua faktor yaitu faktor biologi dan faktor kimia. Faktor bagian jaringan tanaman yang digunakan[11]. Sedangkan faktor kimia berkaitan dengan kandungan senyawa metabolit sekuder pada tanaman. Faktor lain yang berpengaruh pada penghambatan pertumbuhan bakteri adalah pemilihan media, pelarut yang digunakan, ketebalan media, pelarut yang digunakan dan konsentrasi ekstrak metanol yang digunakan. Ekstrak metanol akar $R$. apiculata tidak menunjukkan zona hambat terhadap bakteri E. coli pada berbagai variasi konsentrasi dan selama pengamatan (waktu inkubasi) 12-72 jam, karena bakteri E. coli merupakan bakteri gram-negatif dimana struktur selnya lebih kompleks dan terdiri atas tiga lapisan yaitu lapisan (lipoprotein), lapisan tengah (lipopolisakarida), dan lapisan dalam (peptidoglikan) [12].

\section{KESIMPULAN}

Senyawa golongan metabolit sekunder yang terkandung dalam ekstrak akar mangrove $R$. apiculata adalah senyawa alkaloid, flavonoid, dan triterpenoid. Ekstrak metanol akar mangrove $R$. apiculata menunjukkan aktivitas anti bakteri tertinggi dengan diameter zona hambat $8,3 \mathrm{~mm}$ pada konstrasi $500 \mu \mathrm{g} /$ well dengan waktu inkubasi 48 jam terhadap bakteri $S$. aureus dan tergolong kategori lemah. Ekstrak metanol akar mangrove $R$. apiculata Tidak menunjukkan daya hambat terhadap pertumbuhan bakteri E. coli.

\section{UCAPAN TERIMA KASIH}

Penulis sampaikan kepada Ibu Harlinda Kuspradini, Ph.D. selaku Kepala Laboratorium Kimia Hasil Hutan Fakultas Kehutanan Universitas Mulawarman atas bantuan dalam pengujian aktivitas antibakteri dan Mahasiswa/Mahasiswi Prodi S1 Pendidikan Kimia FKIP Universitas Mulawarman Angkatan 2012 yang melakukan penelitian laboratorium.

\section{DAFTAR RUJUKAN}

[1] Sutarno S. "Potensi dan Manfaat Tumbuhan Mangrove Sebagai Sumber Bahan Bioaktif", Acta Pharmaceutica Indonesia. 12(4), 84-103, 2000.

[2] Mukharromah R.R dan Suyatno. "Senyawa Metabolit Sekunder dari Ekstrak Diklorometana Kulit Batang Bakau Merah ( $R$. Stylosa)". UNESA Jaurnal of Chemistry. Vol.3, No.3, 2014.

[3] Rohmah I.F, Tukira. "Uji Bioaktivitas Ekstrak Kloroform Mangrove Rhizophora apiculata Blume terhadap Spodoptera littura Fabr Sebagai Insektisida Nabati", Prosiding Seminar Nasional Unesa ISBN :978-979-028-550-7, Surabaya 25 Februari 2012.

[4] Li, D.L. et al., "Flavonol Derivaties from $R$. stylosa and Their DPPH Radical Scavening Activity", Molecules 12: 1163-1169, 2007. 
[5] Diastuti H dan Warsinah. "Identifikasi Senyawa Antikanker dari Ekstrak Kloroform Kulit Batang Rhizophora mucronata". Majalah Farmasi Indonesia, 21(14), 266-271, 2010.

[6] Sutiman dan Elli Rohaeti. Teknologi Pembelajaran. FMIPA UNY. Yogyakarta, 2010.

[7] Bandaranayake W.M., "Bioactivities, Bioaktive Compounds of Chemical Constituen and Mangrove Plants". Wetlands Ecology and Management Journal, 10: 421 - 452, 2002.

[8] Suciati A. et al., "Efektivitas Ekstrak Daun Rhizophora mucronata Dalam Menghambat Pertumbuhan Aeromonas salmonicida dan Vibrio harveyi". EJurnal Rekayasa dan Teknologi Budidaya Perairan. 1(1), ISSN:23023600, 2012.
[9] Harborne, Metode Fitokimia: Penentuan Cara Modern Menganalisis Tumbuhan: K. Padmawinata dan I Soediro. Penerbit ITB, Bandung, 1987.

[10] Sjahid, I.R., "Isolasi dan Identifikasi Flavonoid dari Daun Dewandaru (Eugenia uniflora L)" Skripsi Universitas Muhammadiyah Surakarta, 2008.

[11] Sawitti M.Y. et al., "Daya Hambat Perasan Daun Sambiloto Terhadap Pertumbuhan Bakteri E. coli". Indonesia Medicus Veterinus 2(2): 142-150, 2013

[12] Park S.B.T. and T.S. Jung. "Pathogenesis of and Strategiesw for Preventing Edwardsiella tarda Infections in Fish". Veterinary Research 43: 67-72, 2012. 